\title{
Digestibilidade, desempenho e características morfofisiológicas do trato digestório de leitões desmamados sob dietas com mananoligossacarídeo
}

\author{
Vivian Maia dos Santos(1), Maria Cristina Thomaz ${ }^{(1)}$, Leonardo Augusto Fonseca Pascoal(2), \\ Urbano dos Santos Ruiz(1), Pedro Henrique Watanabe(2), Rizal Alcides Robles Huaynate(1), \\ Susana Zaneti da Silva( ${ }^{(1)}$ e Henrique Gonzáles de Faria(1)
}

\begin{abstract}
(1)Universidade Estadual Paulista, Faculdade de Ciências Agrárias e Veterinárias, Via de acesso Prof. Dr. Paulo Donato Castellane, s/no, CEP 14884-900 Jaboticabal, SP. E-mail: vi_maia@hotmail.com, thomaz@fcav.unesp.br, usruiz@yahoo.com.br, rizal3@hotmail.com, educazoo@hotmail.com.br, hgfaria@yahoo.com.br (2)Universidade Federal da Paraíba, Centro de Ciências Humanas, Sociais e Agrárias, Campus III, s/no, CEP 58225-000 Bananeiras, PB. E-mail: leonardo@cchsa.ufpb.br, pedrowatanabe@cchsa.ufpb.br
\end{abstract}

\begin{abstract}
Resumo - O objetivo deste trabalho foi avaliar o efeito da adição do prebiótico mananoligossacarídeo (MOS) nas dietas de leitões sobre a digestibilidade dos nutrientes, o desempenho e as características morfofisiológicas do trato digestório. No primeiro experimento, foram utilizados 16 leitões com peso de 24,8 $2,79 \mathrm{~kg}$. Utilizou-se o método de coleta total de fezes para determinar a digestibilidade das rações controle e com $0,5 \%$ de prebiótico. No segundo experimento, avaliaram-se o desempenho e a incidência de diarreia em 30 leitoas com idade entre 22 e 63 dias e peso inicial de $6,28 \pm 1,40 \mathrm{~kg}$. No terceiro experimento, foram avaliados a morfometria intestinal, os pesos relativos do fígado e do pâncreas e o pH dos conteúdos do estômago, intestino delgado e ceco em 15 leitoas com idade entre 22 e 63 dias e peso inicial de 5,74 $\pm 0,93 \mathrm{~kg}$. No segundo e terceiro experimentos, os tratamentos foram: controle positivo (dieta basal + sulfato de neomicina); controle negativo (dieta basal) e os tratamentos dieta basal acrescida de $0,25,0,50$ ou $0,75 \%$ de MOS. Utilizou-se o delineamento em blocos ao acaso. A utilização de diferentes níveis de mananoligassacarídeo nas dietas dos leitões não promove melhorias na digestibilidade dos nutrientes, no desempenho ou nas características morfofisiológicas do trato digestório.
\end{abstract}

Termos para indexação: diarreia, imunidade, nutrição animal, prebiótico, ração.

\section{Digestibility, performance and morphophysiological characteristics of the digestive tract of weaned piglets under diets with mannanoligosaccharides}

\begin{abstract}
The objective of this work was to evaluate the effect of adding mannanoligosaccharides (MOS) to piglet diets on digestibility of nutrients, performance and morphophysiological characteristics of the digestive tract. In the first experiment, 16 piglets with a weight of $24.8 \pm 2.79 \mathrm{~kg}$ were used. Total feces were collected to determine the digestibility of the control feed and feed with $0.5 \%$ prebiotic. In the second experiment, 30 gilts with ages ranging from 22 to 63 days and a mean weight of $6.28 \pm 1.40 \mathrm{~kg}$ were used to evaluate diarrhea performance and incidence. In the third experiment, 15 gilts ranging from 22 to 63 days in age and a mean weight of $5.74 \pm 0.93 \mathrm{~kg}$ were used to evaluate intestinal morphology, relative weight of the liver and pancreas, and $\mathrm{pH}$ of the stomach, small intestine and cecum contents. In the second and third experiments, the treatments used were: positive control (basal diet + neomycin sulfate), negative control (basal diet) and basal diet with $0.25,0.50$ or $0.75 \%$ of MOS added. The experimental design was in randomized blocks. The use of different levels of MOS in piglet diets does not promote better digestibility of the nutrients, performance and morphophysiological characteristics of digestive tract.
\end{abstract}

Index terms: diarrhea, immunity, animal nutrition, prebiotics, feed.

\section{Introdução}

O período pós-desmama é considerado o mais preocupante na produção de suínos, pois é quando o sistema digestório dos leitões passa por modificações até ficar apto a realizar a digestão de alimentos sólidos (Aumaitre, 2000).

A imaturidade do sistema digestório e as mudanças nas estruturas do intestino explicam o baixo consumo de ração nos primeiros dias pós-desmame, que resulta em atrasos no ganho de peso desses animais. Nessa fase, também é muito comum a proliferação de bactérias patogênicas no trato gastrintestinal, que causam diarreia e ainda morte de leitões (Kelly \& King, 2001).

$\mathrm{Na}$ tentativa de controlar estes problemas, o uso de antibióticos em níveis subterapêuticos nas rações 
tornou-se uma estratégia nutricional, por atuar na redução da população bacteriana patogênica no trato gastrintestinal. Porém, existe crescente pressão para proibir o uso desses produtos como promotores de crescimento. Com isso, tem crescido a busca por produtos alternativos, que tragam aos animais os mesmos benefícios oferecidos pelos antibióticos (Santos et al., 2003; Budiño et al., 2005). Nesse contexto, surgiu o interesse dos pesquisadores pelos prebióticos, que são açúcares complexos que, adicionados às rações, agem como substrato, estimulando o crescimento de diversas bactérias intestinais não patogênicas. Esses substratos são utilizados para ajudar na manutenção da eficiência digestiva, na integridade do epitélio intestinal e na modulação do sistema imunológico (Mikkelsen et al., 2003). Os prebióticos são representados principalmente pelos frutoligossacarídeos, glucoligossacarídeos e mananoligossacarídeos (Utiyama et al., 2006).

Os mananoligossacarídeos atuam sobre as bactérias patogênicas, inibindo sua fixação na parede da mucosa intestinal e aumentando a imunidade (Spring et al., 2000). Esses aditivos são obtidos a partir de leveduras e têm uma cadeia complexa de manose fosforilada, glucose e proteína (Silva \& Nörnberg, 2003). Miguel et al. (2004) observaram que a adição de mananoligossacarídeos à dieta promoveu melhorias no desempenho produtivo de leitões desmamados. Estudos indicaram que os prebióticos teriam capacidade de provocar modificações benéficas nas características anatômicas do trato digestório, promovendo aumento na área de absorção da mucosa intestinal de leitões (Howard et al., 1995; Davis et al., 2002; Castillo et al., 2008).

O objetivo deste trabalho foi avaliar o efeito da adição de mananoligossacarídeos (MOS) às dietas de leitões desmamados sobre a digestibilidade das rações, o desempenho e as características morfofisiológicas do trato digestório.

\section{Material e Métodos}

Os protocolos experimentais (n⿳0 $03.448 / 10$ ) utilizados neste trabalho foram aprovados pela Comissão de Ética no Uso de Animais da Universidade Estadual Paulista (Unesp), Jaboticabal, São Paulo.

Foram realizados três experimentos no Setor de Suinocultura do Departamento de Zootecnia da Faculdade de Ciências Agrárias e Veterinárias da Unesp, campus de Jaboticabal. No primeiro experimento, foram avaliados a digestibilidade e o metabolismo das dietas em 16 suínos da linha Topigs, machos castrados, com 60 dias de idade e com $24,8 \pm 2,79 \mathrm{~kg}$ de peso inicial, os quais foram alojados em gaiolas para estudos metabólicos semelhantes às descritas por Pekas (1968).

$\mathrm{O}$ delineamento experimental utilizado foi $\mathrm{o}$ de blocos ao acaso, com dois tratamentos e oito repetições, e a unidade experimental foi constituída por um animal, num total de oito animais por tratamento. Os tratamentos foram constituídos de dietas (Tabela 1) compostas principalmente por milho e farelo de soja, sem prebiótico (controle) e com $0,5 \%$ de mananoligossacarídeo (MOS), formuladas para atender as exigências nutricionais mínimas recomendadas pelo National Research Council (1998). A quantidade de mananoligossacarídeo utilizada foi recomendada pelo fabricante do produto. Foi utilizado o método de coleta total de fezes.

Os animais foram alojados nas gaiolas de estudos metabólicos durante 12 dias; os sete primeiros para adaptação às gaiolas e rações e para determinação do consumo individual de ração e os cinco últimos para coleta de fezes e urina. $\mathrm{O}$ arraçoamento foi realizado duas vezes ao dia, às $8 \mathrm{he} 17 \mathrm{~h}$, com as rações previamente pesadas e, em seguida, umedecidas, e a água de bebida foi fornecida à vontade. $\mathrm{O}$ óxido férrico foi utilizado como marcador fecal, para determinar o início e o fim do período de coleta. As fezes foram coletadas e pesadas duas vezes ao dia, e foram posteriormente mantidas congeladas. A urina foi coletada diariamente em baldes de plástico e filtrada. $\mathrm{O}$ volume produzido foi mensurado, e uma alíquota de $20 \%$ foi mantida congelada. Ao fim do período de coleta, as fezes e a urina de cada animal foram descongeladas, homogeneizadas e amostradas.

Nas amostras de fezes e de ração, foram realizadas análises de: matéria seca (MS); matéria mineral $(\mathrm{MM})$; extrato etéreo (EE); proteína bruta (PB); fibra em detergente neutro (FDN); fibra em detergente ácido (FDA), de acordo com a metodologia descrita por Silva \& Queiroz (2002); e energia bruta (EB), em bomba calorimétrica do tipo Parr modelo 6400, (Parr Instrument Company, Moline, Illinois, EUA). Nas amostras de urina, foram determinadas as densidades e posteriormente realizadas as análises de EB em bomba calorimétrica do tipo Parr. Essas análises foram realizadas no Laboratório de Nutrição 
Animal do Departamento de Zootecnia da Faculdade de Ciências Agrárias e Veterinárias da Unesp, campus de Jaboticabal.

Foram calculados os coeficientes de digestibilidade de MS, PB, EE, MM, FDN, FDA e EB, assim como os respectivos nutrientes $\mathrm{e}$ a energia digestível das rações. Também foi calculado o coeficiente de metabolizabilidade da energia bruta e, consequentemente, foi obtida a energia metabolizável (EM). Esses cálculos foram realizados de acordo com Adeola (2001).

No segundo experimento, foram avaliados $\mathrm{o}$ desempenho e a incidência de diarreia em 30 fêmeas Topigs desmamadas aos 22 dias de idade e com peso inicial de $6,28 \pm 1,40 \mathrm{~kg}$, alimentadas com rações com diferentes percentagens de MOS. Os animais foram alojados em baias individuais de $2,55 \mathrm{~m}^{2}$ cada uma, com piso de concreto, separadas por divisórias de grades de ferro, equipadas com bebedouros do tipo vaso comunicante, comedouros do tipo semi-automático e escamoteadores de madeira.
As dietas utilizadas foram isonutritivas e isentas de qualquer produto com ação antidiarreica, corretamente suplementadas com minerais e vitaminas, de forma a atender às exigências nutricionais mínimas dos leitões, e tiveram como referência para a composição nutricional dos ingredientes os valores propostos por Rostagno et al. (2005) e os níveis de exigência nutricional preconizados pelo National Research Council (1998). Durante a fase experimental, os animais receberam ração e água à vontade, assim como iguais condições de manejo.

Os tratamentos experimentais foram: controle positivo (CP) - dieta basal + antibiótico (sulfato de neomicina $56 \mathrm{mg} \mathrm{kg}^{-1}$ ); controle negativo $(\mathrm{CN})-$ dieta basal e os tratamentos $\mathrm{CN}+0,25 \%$ de MOS; $\mathrm{CN}+0,50 \%$ de MOS; $\mathrm{CN}+0,75 \%$ de MOS. As rações experimentais (dieta basal) foram formuladas de acordo com a idade dos leitões, e cada formulação foi fornecida nas seguintes fases: 1 , dos 22 aos 35 dias de idade; 2, dos 36 aos 49 dias de idade; e 3, dos 50 aos 63 dias de idade. A composição e os níveis nutricionais das rações experimentais encontram-se na Tabela 1.

Tabela 1. Composição centesimal e níveis nutricionais e energéticos das rações utilizadas nos experimentos 1 (digestibilidade e metabolismo das dietas), 2 e 3 (desempenho, incidência de diarreia e características morfofisiológicas).

\begin{tabular}{|c|c|c|c|c|c|}
\hline \multirow[t]{2}{*}{ Ingrediente (\%) } & \multicolumn{2}{|c|}{ Experimento 1} & \multicolumn{3}{|c|}{ Experimentos 2 e 3} \\
\hline & Ração controle & Ração com MOS ${ }^{(1)}$ & 22 a 35 dias de idade & 36 a 49 dias de idade & 50 a 63 dias de idade \\
\hline Milho & 63,82 & 63,82 & 43,24 & 48,40 & 63,82 \\
\hline Farelo de soja & 24,26 & 24,26 & 27,39 & 25,13 & 24,26 \\
\hline Açúcar & 3,00 & 3,00 & 4,73 & 4,00 & 3,00 \\
\hline Fosfato bicálcico & 1,44 & 1,44 & 1,80 & 1,27 & 1,44 \\
\hline Calcário calcítico & 0,63 & 0,63 & 0,63 & 0,85 & 0,63 \\
\hline Inerte & - & - & 0,75 & 0,75 & 0,75 \\
\hline Sal comum & 0,30 & 0,30 & 0,30 & 0,30 & 0,30 \\
\hline Suplemento vitamínico/mineral ${ }^{(3)}$ & 0,10 & 0,10 & 0,10 & 0,10 & 0,10 \\
\hline L-lisina $\mathrm{HCl}(78 \%)$ & 0,34 & 0,34 & 0,51 & 0,39 & 0,34 \\
\hline DL-metionina $(98 \%)$ & 0,06 & 0,06 & 0,31 & 0,23 & 0,06 \\
\hline L-treonina $(99 \%)$ & 0,09 & 0,09 & 0,22 & 0,14 & 0,09 \\
\hline Prebiótico & - & 0,50 & - & - & - \\
\hline Veículo & 0,75 & 0,25 & - & - & - \\
\hline BHT & 0,01 & 0,01 & 0,01 & 0,01 & 0,01 \\
\hline Total & 100,00 & 100,00 & 100,00 & 100,00 & 100,00 \\
\hline Energia metabolizável $\left(\mathrm{kcal} \mathrm{kg}^{-1}\right)$ & 3.229 & 3.229 & 3.325 & 3.325 & 3.229 \\
\hline Proteína bruta $(\%)$ & 18,30 & 18,30 & 22,20 & 21,00 & 18,30 \\
\hline Cálcio $(\%)$ & 0,72 & 0,72 & 0,88 & 0,83 & 0,72 \\
\hline Fósforo disponível (\%) & 0,40 & 0,40 & 0,56 & 0,45 & 0,40 \\
\hline Lisina digestível (\%) & 1,11 & 1,11 & 1,26 & 1,11 & 0,94 \\
\hline Metionina + cisteína digestível $(\%)$ & 0,63 & 0,63 & 0,71 & 0,63 & 0,53 \\
\hline Metionina digestível (\%) & 0,30 & 0,30 & 0,34 & 0,30 & 0,26 \\
\hline Treonina digestível (\%) & 0,66 & 0,66 & 0,75 & 0,66 & 0,56 \\
\hline Triptofano digestível (\%) & 0,19 & 0,19 & 0,22 & 0,19 & 0,16 \\
\hline
\end{tabular}


No estudo de desempenho, foram avaliados o ganho diário de peso (GDP), o consumo diário de ração (CDR) e a conversão alimentar (CA). Essas variáveis foram calculadas a partir das pesagens dos animais aos 22, 35, 49 e 63 dias de idade, quando foi realizada também a avaliação do consumo de ração para obtenção do GDP, do CDR e da CA. A ração desperdiçada dos comedouros foi recolhida antes da limpeza diária das baias, quantificada e descontada do consumo. Como não houve redistribuição dos animais de acordo com o peso ao início das fases 2 e 3, a análise dos dados de desempenho dividiu-se nos seguintes períodos: 1 , dos 22 aos 35 dias de idade; 2 , dos 22 aos 49 dias de idade; e 3, dos 22 aos 63 dias de idade.

Durante os primeiros 16 dias do período experimental, dos 22 aos 37 dias de idade, os leitões e suas fezes foram observados, sempre pelo mesmo observador, uma vez ao dia, às $8 \mathrm{~h} 00$, com o objetivo de verificar a influência dos tratamentos sobre a incidência de diarreia, conforme Vassalo et al. (1997). Mediante análise visual, as fezes foram classificadas adotando-se os seguintes critérios: 1, fezes com consistência normal; 2 , fezes pastosas; e 3, fezes moles ou aquosas, considerado como presença de diarreia. As observações foram tabuladas e calculou-se a percentagem de incidência de diarreia sobre o total de observações registradas para os 30 animais.

Foi utilizado o delineamento em blocos ao acaso, com cinco tratamentos (dietas utilizadas) e seis repetições, com unidades experimentais constituídas por um animal, num total de seis animais por tratamento.

No terceiro experimento, o desenvolvimento da mucosa intestinal e os parâmetros fisiológicos do trato digestório foram avaliados em 15 fêmeas desmamadas aos 22 dias de idade, em média, com peso inicial de $5,74 \pm 0,93 \mathrm{~kg}$ e de mesma genética (Topigs). $\mathrm{O}$ delineamento utilizado foi o de blocos ao acaso, com cinco tratamentos e três repetições, e a unidade experimental foi constituída por um animal. As rações experimentais foram formuladas de acordo com a idade dos leitões e fornecidas nas seguintes fases: 1 , dos 22 aos 35 dias de idade; 2 , dos 36 aos 49 dias de idade; e 3 , dos 50 aos 63 dias de idade.

As dietas experimentais (dieta basal) foram as mesmas utilizadas no segundo experimento (Tabela 1). Quando os animais completaram 63 dias de idade, foram pesados e abatidos. As vísceras foram imediatamente expostas por uma incisão mediana, e as seções do trato gastrintestinal foram assepticamente isoladas com dupla ligadura. O fígado e pâncreas foram retirados e pesados, para o cálculo dos pesos relativos $\left(\mathrm{g} \mathrm{kg}^{-1}\right)$ por meio da divisão do peso absoluto do órgão pelo peso do animal obtido na última pesagem. Em seguida, coletaram-se amostras de $\pm 3 \mathrm{~cm}$ do duodeno e da porção média do jejuno, para confecção de lâminas histológicas. Também foi medido o $\mathrm{pH}$ dos conteúdos do estômago, intestino delgado e ceco. O processamento das amostras e a leitura das lâminas foram realizados nos Laboratórios de Histologia e de Anatomia, respectivamente, no Departamento de Morfologia e Fisiologia Animal da Faculdade de Ciências Agrárias e Veterinárias da Unesp, campus de Jaboticabal.

Para as leituras das lâminas histológicas, utilizou-se microscópio de luz modelo Olympus BX41 (Olympus Optical do Brasil Ltda., São Paulo, SP), acoplado a um sistema para captura de imagens Olympus DP11-N (Olympus Optical do Brasil Ltda., São Paulo, SP) e sistema analisador de imagens por meio do programa Image Pro-Plus 4.1 (Media Cybernetics, Bethesda, USA), com aumento de 125 vezes. Os parâmetros avaliados foram altura das vilosidades (AV), profundidade das criptas (PC) e relação AV/PC, e foram realizadas 30 leituras de cada parâmetro por amostra.

Os dados de digestibilidade das dietas, desempenho, morfometria intestinal, peso dos órgãos (fígado e pâncreas), $\mathrm{pH}$ dos conteúdos do estômago, intestino delgado e ceco foram analisados por meio do procedimento "general linear model" (GLM) do SAS (SAS Institute, 1998). As médias dos coeficientes de digestibilidade dos nutrientes e de metabolizabilidade da energia foram comparadas pelo teste F. As médias de desempenho, morfometria intestinal, peso dos órgãos e pH foram submetidas à análise de variância e de regressão para os níveis de MOS - $\mathrm{CN}$ (dieta basal), $\mathrm{CN}+0,25 \%$ de MOS, $\mathrm{CN}+0,50 \%$ de MOS e $\mathrm{CN}+0,75 \%$ de MOS - quando comparados entre si. O tratamento controle positivo (dieta basal + sulfato de neomicina $56 \mathrm{ppm}$ ) foi comparado aos demais tratamentos pelo teste de Dunnet, a 5\% de probabilidade. Para a análise estatística dos dados de incidência de diarreia, utilizou-se o teste não paramétrico de Kruskall-Wallis (5\%). 


\section{Resultados e Discussão}

A ração com MOS promoveu aumentos $(\mathrm{p}<0,05)$ nos coeficientes de digestibilidade da fibra em detergente ácido (Tabela 2), melhorando o aproveitamento dessa fração. Porém, houve redução $(p<0,05)$ no coeficiente de disponibilidade da matéria mineral, o que não era esperado, pois, de acordo com Scholz-Ahrens et al. (2001), a utilização de prebióticos pode aumentar a absorção de minerais, pela maior colonização microbiana do trato gastrintestinal. A digestibilidade dos demais nutrientes não foi influenciada $(p>0,05)$ pela adição de $0,5 \%$ de MOS às rações.

Ao avaliar a digestibilidade de dietas contendo 0,3\% de mananoligossacarídeo em leitões na fase de creche, Utiyama (2004) verificou que o uso de prebiótico (MOS) não melhorou a digestibilidade aparente dos nutrientes, o que concorda com os resultados observados neste trabalho.

Os níveis de adição de $\operatorname{MOS}(\mathrm{CN}, \mathrm{CN}+0,25 \%$, $\mathrm{CN}+0,50 \%$ e $\mathrm{CN}+0,75 \%$ de $\mathrm{MOS}$ ) e o tratamento controle positivo (com adição de sulfato de neomicina $56 \mathrm{ppm})$, não influenciaram $(\mathrm{p}>0,05)$ as variáveis ganho diário de peso, consumo diário de ração e conversão alimentar em nenhum dos períodos

Tabela 2. Coeficientes de digestibilidade (CD) e de metabolizabilidade (CM) e valores de nutrientes digestíveis e energias digestível e metabolizável das dietas contendo ou não o prebiótico mananoligossacarídeo $(\mathrm{MOS})^{(1)}$.

\begin{tabular}{|c|c|c|c|}
\hline Característica & Ração controle & $\operatorname{MOS}^{(2)}$ & CV $(\%)$ \\
\hline & \multicolumn{3}{|c|}{ Coeficientes de digestibilidade e metabolizabilidade } \\
\hline CD MS (\%) & 89,09 & 89,07 & 1,14 \\
\hline CD PB $(\%)$ & 87,90 & 87,84 & 1,13 \\
\hline $\mathrm{CD} \operatorname{EE}(\%)$ & 80,57 & 79,39 & 9,00 \\
\hline CD MM $(\%)$ & $63,85 \mathrm{a}$ & $61,60 \mathrm{~b}$ & 2,59 \\
\hline CD FDN $(\%)$ & 67,08 & 68,57 & 7,65 \\
\hline CD FDA $(\%)$ & $61,40 \mathrm{~b}$ & $68,39 a$ & 5,60 \\
\hline CD EB $(\%)$ & 88,79 & 88,54 & 1,33 \\
\hline \multirow[t]{2}{*}{ CM EB (\%) } & 86,91 & 87,04 & 1,07 \\
\hline & \multicolumn{3}{|c|}{ Nutrientes digestíveis e energias digestível e metabolizáve } \\
\hline MS (\%) & 79,40 & 79,74 & 1,14 \\
\hline $\mathrm{PB}(\%)$ & 16,70 & 16,23 & 3,15 \\
\hline $\mathrm{EE}(\%)$ & 3,58 & 3,41 & 11,33 \\
\hline MM (\%) & $3,17 \mathrm{a}$ & $2,63 b$ & 2,41 \\
\hline FDN $(\%)$ & 7,06 & 7,68 & 24,84 \\
\hline FDA $(\%)$ & $2,68 b$ & $3,43 a$ & 5,31 \\
\hline $\mathrm{ED}\left(\mathrm{kcal} \mathrm{kg}^{-1}\right)$ & 3.549 & 3.536 & 1,56 \\
\hline $\mathrm{EM}\left(\mathrm{kcal} \mathrm{kg}^{-1}\right)$ & 3.463 & 3.473 & 1,90 \\
\hline
\end{tabular}

${ }^{(1)} \mathrm{MS}$, matéria seca; PB, proteína bruta; EE, extrato etéreo; MM, matéria mineral; FDN, fibra em detergente neutro; FDA, fibra em detergente ácido; EB, energia bruta; ED, energia digestível; EM, energia metabolizável. Médias seguidas de letras diferentes na linha diferem entre si pelo teste F, a $5 \%$ de probabilidade. Médias de oito leitões com 60 dias de idade. ${ }^{(2)}$ Ração com $0,5 \%$ de mananoligossacarídeo (MOS). avaliados. Alguns trabalhos demonstraram resultados favoráveis à utilização de prebióticos como substitutos aos antibióticos promotores de crescimento em dietas para leitões. Miguel et al. (2004), ao analisar dados de 54 experimentos, verificaram aumentos de $4,12 \%$ no ganho de peso, $2,11 \%$ no consumo de ração e $2,29 \%$ na eficiência alimentar de leitões que receberam dietas contendo MOS como prebiótico. Castillo et al. (2008), ao utilizar $0,2 \%$ de MOS nas dietas iniciais de leitões, também observaram melhorias na eficiência alimentar dos animais que consumiram o prebiótico em relação àqueles que receberam dietas contendo zinco na forma orgânica e dieta controle (sem adição de promotor de crescimento).

Mikkelsen et al. (2003), Santos et al. (2003) e Sanches et al. (2006) também não observaram efeitos sobre o desempenho quando adicionaram MOS às dietas de leitões. Isso pode ser um indicativo da falta de desafio sanitário nas instalações onde são conduzidos os experimentos ou da necessidade de mais conhecimento sobre a quantidade exata de prebiótico a ser incluída nas rações, para que possa atuar de forma eficiente no trato digestório e trazer benefícios sobre o desempenho produtivo.

De acordo com valores de escores fecais, não foi observada influência de nenhum dos tratamentos avaliados $(p>0,05)$ sobre a incidência de diarreia. $O$ uso de mananoligossacarídeos tem sido recomendado para promoção de crescimento em dietas para leitões desmamados, pela modificação do ecossistema gastrintestinal, o que pode reduzir a colonização por bactérias patogênicas e, consequentemente, a incidência de diarreia pós-desmame (Silva \& Nörnberg, 2003). Nesse sentido, Utiyama et al. (2006), ao avaliar a frequência de diarreia em leitões recém-desmamados, constataram que o uso de $0,3 \%$ de prebiótico (MOS) foi eficaz no controle de diarreia. $\mathrm{O}$ mesmo efeito foi verificado por Grela et al. (2006), que, ao avaliar a adição de $0,3 \%$ de MOS em dietas para leitões desmamados aos 28 dias de idade, afirmaram que o uso de prebiótico diminuiu a incidência de diarreia e promoveu melhor resposta no desempenho dos animais. Entretanto, resultados semelhantes aos encontrados no presente trabalho foram observados por outros autores (Budiño et al., 2006; Castillo et al., 2008), que não verificaram efeitos dos prebióticos no controle da diarreia.

Os valores de altura das vilosidades (AV), profundidade das criptas (PC) e relação AV/PCavaliados 
no duodeno e jejuno dos leitões não apresentaram diferenças $(p>0,05)$ entre os tratamentos avaliados. Resultados semelhantes aos encontrados neste trabalho foram relatados por Budiño et al. (2005), que não observaram diferenças na morfometria intestinal de leitões recém-desmamados alimentados com ração contendo prebiótico. Castillo et al. (2008) trabalhando com $0,2 \%$ de MOS nas rações de leitões desmamados, não encontraram diferenças em $\mathrm{AV}, \mathrm{PC}$ e $\mathrm{AV} / \mathrm{PC}$ no duodeno e jejuno dos animais em comparação aos animais alimentados com dieta contendo zinco na forma orgânica ou dieta controle, sem a adição de qualquer promotor de crescimento. Os pesos relativos do fígado e do pâncreas não foram influenciados $(p>0,05)$ pelos tratamentos. Alguns autores (Ferket, 2002; Silva \& Nörnberg, 2003) relataram que o MOS é reconhecido como estimulador do sistema imune humoral e gera economia de nutrientes por não causar estímulo crônico ativo de defesa. Sanches (2004) não encontrou efeito do prebiótico sobre os pesos absolutos e relativos do fígado, pâncreas e baço. Da mesma forma, Utiyama (2004) trabalhando com antimicrobianos, probióticos, prebióticos e extratos vegetais nas rações de leitões recém-desmamados tampouco encontrou efeitos do prebiótico sobre os pesos relativos do fígado, do pâncreas e do baço.

Ferket (2002) relatou que os mananoligossacarídeos podem inibir a proliferação de bactérias patogênicas, o que possibilita a colonização por bactérias lácticas benéficas e, consequentemente, pode haver redução do $\mathrm{pH}$ do bolo intestinal, o que não foi verificado no presente trabalho. Santos et al. (2003), ao trabalhar com diversos níveis de manose, encontraram valores de $\mathrm{pH}$ que variaram de 3,4 a 3,7 para os conteúdos do estômago e de 5,2 a 5,4 para os do ceco, muito próximos aos encontrados no presente trabalho.

A utilização dos níveis de mananoligossacarídeo nas dietas dos leitões não promove melhorias na digestibilidade dos nutrientes, no desempenho ou nas características morfofisiológicas do trato digestório.

\section{Conclusões}

1. A digestibilidade dos nutrientes não é influenciada pela adição de mananoligossacarídeo às rações, exceto para digestibilidade da fibra em detergente ácido.

2. O desempenho avaliado por ganho diário de peso, consumo diário de ração e conversão alimentar não é influenciado pela adição de mananoligossacarídeo à ração.

3. A adição de mananoligossacarídeo às rações não influencia a incidência de diarreia nos leitões ou nas características morfofisiológicas do trato digestório dadas por morfometria intestinal, peso do fígado, peso do pâncreas e $\mathrm{pH}$ dos conteúdos do sistema digestório.

\section{Referências}

ADEOLA, O. Digestion and balance techniques in pigs. In: LEWIS, A.J.; SOUTHERN, L.L. Swine Nutrition. $2^{\text {nd }}$ ed. Boca Raton: CRC Press, 2001. p.903-916.

AUMAITRE, L.A. Adaptation and efficiency of the digestive process in the gut of the young piglet: consequences for the formulation of a weaning diet. Asian Australasian Journal of Animal Science, v.13, p.227-242, 2000. Special issue, swine nutrition session.

BUDIÑO, F.E.L.; THOMAZ, M.C.; KRONKA, R.N.; NAKAGHI, L.S.O.; TUCCI, F.M.; FRAGA,A.L.; SCANDOLERA, A.J.; HUAYNATE, R.A.R. Effect of probiotic and prebiotic inclusion in weaned piglet diets on structure and ultra-structure of small intestine. Brazilian Archives of Biology and Technology, v.48, p.921-929, 2005.

BUDIÑO, F.E.L.; THOMAZ, M.C.; KRONKA, R.N.; TUCCI, F.M.; FRAGA, A.L.; SCANDOLERA, A.J.; HUAYNATE, R.A.R.; NADAI, A.; CORREIA, R.C. Efeito da adição de probiótico e/ou prebiótico em dietas de leitões desmamados sobre o desempenho, incidência de diarréia e contagem de coliformes totais. Brazilian Journal of Veterinary Research and Animal Science, v.43, p.59-67, 2006.

CASTILLO, M.; MARTÍN-ORÚE, S.M.; TAYLOR-PICKARD, J.A.; PEREZ, J.F.; GASA, J. Use of mannan-oligosaccharides and zinc chelate as growth promoters and diarrhea preventative in weaning pigs: effects on microbiota and gut function. Journal of Animal Science, v.86, p.94-101, 2008.

DAVIS, M.E.; MAXWELL, C.V.; BROWN, D.C.; RODAS, B.Z. de; JOHNSON, Z.B.; KEGLEY, E.B.; HELLWIG, D.H.; DVORAK, R.A. Effect of dietary mannan oligosaccharides and (or) pharmacological additions of copper sulfate on growth performance and immunocompetence of weanling and growing/finishing pigs. Journal of Animal Science, v.80, p.2887-2894, 2002.

FERKET, P.R. Use of oligosaccharide and gut modifiers as replacements for dietary antibiotics. In: MINNESOTANUTRITION CONFERENCE, 63., 2002, Indianapolis. Proceedings. Indianapolis: UIL, 2002. p.169-182.

GRELA, E.R.; SEMENIUK, V.; CZECH, A. Efficacy of fructooligosaccharides and mannanoligosaccharides in piglet diets. Medycyna Weterynaryjna, v.62, p.762-766, 2006.

HOWARD, M.D.; GORDON, D.T.; PACE, L.W.; GARLEB, K.A.; KERLEY, M.S. Effects of dietary supplementation with fructooligosaccharides on colonic microbiota populations and 
epithelial cell proliferation in neonatal pigs. Journal of Pediatric Gastroenterology and Nutrition, v.21, p.297-303, 1995.

KELLY, D.; KING, T.P. Digestive physiology and development in pigs. In: VARLEY, M.A.; WISEMAN, J. (Ed.). The weaner pig: nutrition and management. Wallingford: CABI, 2001. p.179-206.

MIGUEL, J.C.; RODRIGUEZ-ZAS, S.L.; PETTIGREW, J.E. Efficacy of a mannan oligosaccharide (Bio-Mos) for improving nursery pig performance. Journal of Swine Health and Production, v.12, p.296-307, 2004.

MIKKELSEN, L.L.; JAKOBSEN, M.; JENSEN, B.B. Effects of dietary oligosaccharide on microbial diversity and fructo-oligosaccharide degrading bacteria in faeces of piglets post-weaning. Animal Feed Science and Technology, v.109, p.133-150, 2003.

NATIONALRESEARCHCOUNCIL. Nutrient requirement of swine. $10^{\text {th }}$ ed. Washington: National Academic of Sciences, 1998. 190p.

PEKAS, J.C. Versatile swine laboratory apparatus for physiologic and metabolic studies. Journal of Animal Science, v.27, p.1303-1309, 1968.

ROSTAGNO, H.S.; ALBINO, L.F.T.; DONZELE, J.L.; GOMES, P.C.; OLIVEIRA, R.F.; LOPES, D.C.; FERREIRA, A.S.; BARRETO, S.L.T. Tabelas brasileiras para aves e suínos: composição dos alimentos e exigências nutricionais. 2.ed. Viçosa: UFV, 2005. 186p.

SANCHES, A.L. Probiótico, prebiótico e simbiótico em rações de leitões ao desmame. 2004. 63p. Dissertação (Mestrado) Universidade Federal de Lavras, Lavras.

SANCHES, A.L.; LIMA, J.A. de F.; FIALHO, E.T.; MURGAS, L.D.S.; ALMEIDA, E.C. de; VIEIRA NETO, J.; FREITAS, R.T.F. de. Utilização de probiótico, prebiótico e simbiótico em rações de leitões ao desmame. Ciência e Agrotecnologia, v.30, p.774-777, 2006.
SANTOS, W.G. dos; FILGUEIRAS, E.P.; BERTECHINI, A.G.; FIALHO, E.T.; LIMA, J.A. de F.; BRITO, M.A.V. de P. Manose na alimentação de leitões na fase de creche (desempenho, $\mathrm{pH}$ do trato gastrintestinal e peso dos órgãos). Ciência e Agrotecnologia, v.27, p.696-702, 2003.

SAS INSTITUTE. SAS user's guide: statistics. Cary: SAS Institute, 1998. 956p.

SCHOLZ-AHRENS, K.E.; SCHAAFSMA, G.; VAN DEN HEUVEL, E.G.H.M.; SCHREZENMEIR, J. Effects of prebiotics on mineral metabolism. The American Journal of Clinical Nutrition, v.73, p.459-464, 2001. Supplement.

SILVA, D.J.; QUEIROZ, A.C. Análise de alimentos, métodos químicos e biológicos. 2.ed. Viçosa: UFV, 2002. 235p.

SILVA, L.P. da; NÖRNBERG, J.L. Prebióticos na nutrição de não ruminantes. Ciência Rural, v.33, p.983-990, 2003.

SPRING, P.; WENK, C.; DAWSON, K.A.; NEWMAN, K.E. The effects of dietary mannan oligosaccharides on cecal parameters and the concentration of enteric bacteria in the ceca of salmonella-challenged broiler chicks. Poultry Science, v.79, p.205-211, 2000.

UTIYAMA, C.E. Utilização de agentes antimicrobianos, probióticos, prebióticos e extratos vegetais, como promotores do crescimento de leitões recém-desmamados. 2004. 94p. Tese (Doutorado) - Escola Superior de Agricultura Luiz de Queiroz, Piracicaba.

UTIYAMA, C.E.; OETTING, L.L.; GIANI, P.A.; RUIZ, U. dos S.; MIYADA, V.S. Efeitos de antimicrobianos, prebióticos, probióticos e extratos vegetais sobre a microbiota intestinal, a freqüência de diarréia e o desempenho de leitões recém-desmamados. Revista Brasileira de Zootecnia, v.35, p.2359-2367, 2006.

VASSALO, M.; FIALHO, E.T.; OLIVEIRA, A.I.G.; TEIXEIRA, A.S.; BERTECHINI, A.G. Probióticos para leitões dos 10 aos $30 \mathrm{~kg}$ de peso vivo. Revista Brasileira de Zootecnia, v.26, p.131-138, 1997.

Recebido em 7 de julho de 2009 e aprovado em 22 de dezembro de 2009 